\title{
La estetosfera en las artes y el retorno del medioevo
}

The aestheticsphere in the arts and the return of the middle ages

\author{
HUGO IGNACIO CAMPOS \\ Escuela de Graduados \\ Facultad de Filosofía y Humanidades \\ Universidad Austral de Chile, Valdivia, Chile \\ hugo.campos.w@gmail.com
}

\section{RESUMEN}

En la semiosfera (Lotman 2000, 1996) posmoderna actual (Lyotard, 1996), el tiempo de las vanguardias ha pasado. Vivimos en una pluralidad de estéticas (Gombrich, 1999) o modos de sensibilidad, que en su más lograda expresión tienen que ver con el placer estético vinculado a las bellas artes (Valery, 2018). Sin embargo, esto empaña la posibilidad anticipadora resolutiva de un horizonte extático de futuro (Heidegger, 2015), si solo se deja ver la diferencia superficial de los entes y no el orden unitario que subyace a estas (Heráclito, 2009), con lo cual se cae en la medianidad de un presente que no reconoce su futuro, ni su pasado (Heidegger, 2015; Jaspers, 1958). Teniendo como base la hipótesis de que una expresión de dicho orden en las artes tiene que ver con que lo más avanzado coincide con lo más tradicional (Gombrich, 1999), se estudiaron textos actuales que hacen referencia a diferentes expresiones artísticas, buscando concurrencias conceptuales (Grondin, 1999), que indicialmente (Ginzburg, 2004) relevaron tal orden subyacente en el modo de una estetosfera como una estructura ontológica de sensitividad, desde la cual emerge en la actualidad una semiosfera epistemológica, entretejida de tensiones entre núcleos conceptuales descentrados que actualizan elementos culturales del medioevo.

Palabras clave: Artes, estetosfera, semiosfera, ontología, epistemología, edad media. 


\section{ABSTRACT}

In the current postmodern (Lyotard, 1996) semiosphere (Lotman 2000, 1996), the time of the avantgardes has passed. We live in a plurality of aesthetic (Gombrich, 1999) or modes of sensitivity which in its most successful expression have to do with the aesthetic pleasure related to fine arts (Valéry, 2018). However, this tarnishes the possibility of an anticipatory resolution of an ecstatic horizon of future (Heidegger, 2015), if only is allowed to see the surface difference of entities and not the unit order that underlies these (Heráclito, 2009), with which we falls in the medium of a present that does not recognize their future or their past (Heidegger, 2015; Jaspers, 1958). Taking as a basis the hypothesis that an expresión of that order in the arts, has to do with the ultimate coincides with the more traditional (Gombrich, 1999), it was studied current texts that refer to different artistic expressions, looking for conceptual convergences (Grondin, 1999) that indexically (Ginzburg, 2004) relieved such underlying in the mode of an aestheticsphere as an ontolical structure of sensitivity, from which emerges an epistemological semiosphere today, interweaving of tensions between decentralized conceptual nuclei that updated cultural elements of the middle ages.

Key words: Arts, aestheticsphere, semiosphere, ontology, epistemology, middle ages.

\section{Introducción ${ }^{1}$}

Las artes nacen de la reflexión sobre el mundo de la vida cotidiana y se elevan y aceleran hasta romper la barrera semiótica de un tiempo determinado, proyectando futuro en las conceptualizaciones estéticas y en las obras de arte. Son por antonomasia las disciplinas liminales de una cultura, que están en su tiempo y, a la vez, más allá de este. La presencia y estado de desarrollo de las artes dan cuenta de un determinado tiempo epocal, de temporeidades residuales y de la presencia de tiempos posibles.

Paul Valéry (2018, p. 22) asume por arte "la calidad de la manera de hacer (sea cual sea el objeto), lo que supone la desigualdad de los modos de operación

\footnotetext{
Una versión extendida de esta introducción se puede encontrar en mi tesis de Doctorado titulada "Fenomenología de la identidad cultural de la Región de los Ríos manifestada en la Nueva Historia de Valdivia de Gabriel Guarda".
} 
y por lo tanto de los resultados -como consecuencia de la desigualdad de los agentes-". La esencia de la calidad de la manera de hacer, Stefan Zweig la descubrió luego de haber observado por una hora y media trabajar a Rodin en su taller, en el que el escultor se había olvidado por completo de la presencia de su visita: "durante esa hora y media descubrí, para siempre, el secreto más recóndito de todo arte y todo perfeccionamiento terrenal: la concentración; la concentración de todas las fuerzas de un hombre sobre el cumplimiento de su tarea, sea ella lo que fuere, grande o pequeña" (2015, p. 75).

Asimismo, "hablamos de arte cada vez que algo está tan superlativamente bien hecho que hasta olvidamos preguntar qué es, de tanto como admiramos el modo en que ha sido realizado" (Gombrich 1999, p. 602). En ese sentido, es apropiado nombrar artes en plural, puesto que en palabras de Gombrich "no existe, realmente, el Arte. Tan solo hay artistas" (1999, p. 15).

Desde los neandertales y los homo sapiens que dibujaban pinturas rupestres en las cavernas prehistóricas, pasando por la pintura que el artista llevaba a la plaza pública en la época clásica y edad media para ser evaluada y comprada por quienes querían saber acerca de la belleza de otros mundos, hasta quienes hoy en día experimentan con los distintos modos de expresión de la imagen técnica en museos, metros y galerías, según Gombrich (1999, p. 15):

"no hay ningún mal en llamar arte a todas estas actividades, mientras tengamos en cuenta que tal palabra puede significar muchas cosas distintas, en épocas y lugares diversos, y mientras advirtamos que el Arte, escrita la palabra con A mayúscula, no existe, pues el Arte con A mayúscula tiene por esencia que ser un fantasma y un ídolo".

Sin embargo, no se debe caer en la idea de desontologizar el mundo al que hace referencia la palabra arte, dado que sin este no habría artista ni obra de arte, puesto que es desde estos mundos del arte donde aquellos obtienen su sentido. En palabras de Heidegger (1996, p. 1):

"el artista es el origen de la obra. La obra es el origen del artista. Ninguno puede ser sin el otro. Ninguno de los dos soporta tampoco al otro por separado. El artista y la obra son en sí mismos y recíprocamente por medio de un tercero que viene a ser lo primero, aquello de donde el artista y la obra de arte reciben sus nombres: el arte". 
Si bien no hay Arte con mayúscula, sí es importante reconocer que hay artes como mundos culturales, en los que artista y obra coemergen, además, obtienen y proyectan sentido hacia otros mundos culturales. Sin duda, los mundos del arte son la cúpula de las culturas, que irrumpen como su baluarte del temple identitario, dotando de sentido los juegos significantes en los distintos planos de existencia.

Según Valéry (2018), al hablar de arte como disciplina, se pueden mencionar dos opciones: la ciencia de lo bello o la ciencia de las sensaciones. Una nos lleva a saber qué es eso que llamamos bello y la otra nos impulsa a pensar sobre qué es sentir. Ambas opciones se complementan, de tal manera que, partiendo de la segunda opción, llegamos inevitablemente a la primera. La reflexión sobre ambas es propiamente la estética. Esta tiene que ver con el placer (Valéry, 2018). Un placer absoluto que no depende de ninguna causa, un placer inútil que está más allá de la necesidad de funcionar y que deja ver algo de la intimidad del fenómeno: es un placer causante vinculado a zonas que

"van más allá del ámbito de la sensibilidad, y la vinculan siempre a la producción de modificaciones afectivas, de aquellas que se prolongan y se enriquecen en las vías del intelecto y llevan en ocasiones a emprender acciones exteriores sobre la materia, sobre el sentido o sobre el espíritu ajeno, exigiendo el ejercicio combinado de todas las capacidades humanas" (Valéry, 2018, p. 40).

En suma, resulta un placer inefable que cuando la estética lo conceptualiza es llamado "idea de lo Bello" (Valéry, 2018, p. 43).

Al respecto, para Heidegger (1996, p. 17) lo bello no es ajeno a la verdad, sino que "es uno de los modos de presentarse de la verdad". Sin embargo, él no entiende la verdad como correspondencia entre representación y realidad, con lo cual gran parte de la belleza y de los objetos bellos quedarían fuera del criterio. En palabras de Heidegger, "la verdad es el desocultamiento de lo ente en cuanto ente. La verdad es la verdad del ser. La belleza no aparece al lado de esta verdad. Se manifiesta cuando la verdad se pone en la obra" (1996, p. 27).

De ese modo, "a la transformación de la esencia de la verdad corresponde la historia de la esencia del arte occidental" (Heidegger, 1996, p. 27), por lo que, al hablar de arte se hace referencia a la idea de lo bello, mientras que la verdad se concibe como el desocultamiento del ente y del mundo histórico que se erige en la obra de arte. 
Una consecuencia de lo anterior es que las artes se relacionan con verdades, en tanto desocultaciones de los entes, en el claro presente en el mundo erigido y en la tierra traída aquí por la obra, en oposición a la negación y apariencia de los mismos, que en su negación permiten la aparición del claro (Heidegger, 1996).

Es necesario, entonces, estudiar el desocultamiento histórico de los entes, pensando aquí en un tipo particular de ente: las ideas artísticas y estéticas, a fin de dar cuenta de las verdades que se hacen patentes como imágenes de los tiempos epocales.

Para Schutz (citado en Ritzer, 2012), el pasado o vorwelt es lo ya sido que resalta desde lo que no fue, por lo que se hará un breve resumen, considerando los conceptos que emergen y se hacen más visibles en la memoria colectiva. El presente es una fusión de conceptos que brotan y se sumergen en el umwelt y el mitwelt, por lo que se presenta más bien como un montaje de collage; el futuro 0 folgewelt es incierto, por lo que no se puede hacer más que proyecciones sobre la base de la extrapolación de los patrones de variación estética desvelados en el vorwelt y en el umwelt y el mitwelt.

No obstante, con base en la hipótesis de que lo más avanzado coincide con lo más tradicional, es posible llevar a cabo un estudio provisional del futuro que se proyecta (Gombrich, 1999).

\section{Método}

Se realizó un entretejimiento intertextual, buscando concurrencias (Grondin, 1999; Poncaire, 1914; Valéry, 2018) o el concurso simultáneo de varias conceptualizaciones en múltiples textos de estética y de teoría del arte, con lo cual se obtuvo la unidad en potencia (Mirandola, 1984) y subyacente (Heráclito, 2009) de los diferentes actos estético y artísticos. Lo anterior, según Poncaire (1914), posibilita el progreso histórico de los mismos y -por extrapolación- de la comunidad semiótica a la que pertenecen, formando cadenas de comunicación discursiva (Bajtin, 2011).

Los textos estudiados fueron producidos entre el 2016 y el 2019 por cinco universidades ( 4 de habla hispana y 1 de habla inglesa), ubicadas estructuralmente (discursiva) y topológicamente (territorialmente) en puntos claves de producción 
semiótica, tanto en el sur como en el norte global del hemisferio occidental: Chile, Argentina, España y Estados Unidos.

Con el criterio de que "con la discusión de las más variadas filosofías [luce] más claro a nuestras mentes aquel fulgor de la verdad, del que habla Platón en sus Cartas" (Mirandola 1984, p. 128), los textos analizados hacen referencia a diversas expresiones artísticas: pintura, poesía, cine, teatro, performance art y ópera. En total, fueron 29 las unidades macrodiscursivas estudiadas.

Las concurrencias conceptuales encontradas fueron interpretadas como indicios microhistóricos (Ginzburg, 2004), que demuestran un paisaje del ambiente espiritual de nuestro tiempo, esto es, la existencia factible o posible claridad del saber con respecto a su situación y ser-mismo en su fe (Jaspers, 1933), o en otros términos, concepciones de mundo (1960) y, a la vez, metáforas (Lizcano, 2006) que habitan el imaginario (Castoriadis, 2007) y la memoria colectiva (Halbwachs, 2004) de la semiosfera (Lotman: 2000, 1996) occidental, dejando observar la existencia concreta de su comunidad de destino, lo que ya ha sido o el pasado (Heidegger, 2015). Lo anterior incluye lo oculto u ominoso (Freud, 1969, p. 66), es decir, aquello "familiar de antiguo a la vida anímica (...) destinado a permanecer oculto [que] ha salido a la luz", clarificando su saber con respecto a dicha facticidad entre los entes intramundanos o el presente (Heidegger, 2015) y preconstruyendo su temple anímico-identitario o la previsión de posibilidades de futuro de la temporeidad epocal (Heidegger, 2015).

El método se basa en la propuesta de Ciocchini (citado en Crespi, 2018, p. 58) para las ciencias humanas, con base en la filología, que se constituye en "una suerte de paráfrasis activa y exhaustiva -aunque inevitablemente inacabada- de todo lo que en la tradición va siendo borrado u olvidado con el paso del tiempo (...)" y "envuelve pacientemente a los objetos de la cultura y apela a la restitución de los sentidos perdidos en la pérdida de los contextos" (Crespi, 2018, p. 58).

El conocimiento logrado es una mirada holística que abarca "lo humano como un todo, trabajando sobre los fundamentos de los distintos saberes, desde una perspectiva general que no se confunde con ninguno de ellos. Las humanidades integran, sintetiza, agregan, recogen, unifican en un mundo de saberes cada vez más dispersos y aislados" (Gandolfo, 2018, p. 41).

Lo anterior no se enmarca en "una racionalidad instrumental, tecnocrática, del pensar calculante que denunciara el gran filósofo alemán Martín Heidegger, del 
pensar unilateral, por una sola vía (...) [sino en] la alternativa de la racionalidad estética, cordial, metafórica o simbólica (...) pero no por ello privada de racionalidad y rigor" (Gandolfo, 2018, p. 41).

\section{Resultados}

\section{Existencia factible}

No es la intención de este estudio enfocarse en lo ya sido, pues eso escaparía a los límites del formato escritural. Por el contrario, se busca nombrar los principales hitos causales de la historia del arte, a modo de un esbozo hecho de un puntilleo que permita entrar en el paisaje conceptual de las discusiones actuales en estética y teoría del arte, con el objetivo de hacer que estas adquieran volumen en la superficie eidética del ahora.

Ahora bien, el arte se ha expresado como un mundo que manifiesta la verdad de los tiempos epocales (Heidegger, 1966), teniendo como antecedente: las pinturas rupestres, la posición ontológica de los egipcios, el descubrimiento del escorzo de los griegos, la profundidad descubierta por Giotto, el estilo internacional normando/ románico, el estilo gótico, el descubrimiento de la perspectiva de Brunelleschi, el redescubrimiento de la belleza del cuerpo humano (Leonardo Da Vinci, Miguel Angelo Buonarroti y Rafael Sanzio), la capacidad de retratar el mundo de los artistas flamencos (como Jean Van Eyck, Hans Memling o Rogier van der Weyden), la capacidad de pintar lo que nadie había visto hasta ahora (como El Bosco o la fuerza de Rubens durante el Barroco), la capacidad de síntesis de Spinoza y el realismo de Goya, la revolución impresionista, su contraparte expresionista y la respuesta fauvista o las vanguardias y el arte posmoderno en el ámbito más amplio de la posmodernidad.

Pero, la verdad del éxtasis temporal de lo ya sido en el arte -contrariando las tesis de Schutz-, se muestra cambiante, pues los descubrimientos que se realizan en el presente cambian nuestras concepciones del pasado, removiendo las verdades fundamentales en el ahora y de lo que aún no ha sido. Tómese como ejemplo el desenterramiento de fragmentos policromados de esculturas de la edad media en Francia, que contradicen la creencia de que estas eran monocromáticas, al igual que muchas obras arquitectónicas que, por su exposición a la luz, habrían perdido sus colores originarios, lo que hace ver una nueva imagen del mundo medieval, menos oscura. Asimismo, el descubrimiento de estatuas griegas en el 
mar mediterráneo, con rasgos más humanos y menos deiformes, son contrarias a la imagen dominante sobre la búsqueda de la belleza, de la belleza con letra capital, en la edad clásica (Gombrich, 1999).

\section{Saber con respecto a nuestra situación}

Aparecer es el concepto utilizado desde el teatro para reemplazar el concepto de representación. En términos metafóricos, hay un reemplazo de la imagen del escenario como un espejo que refleja el mundo de la vida cotidiana, por una imagen como un mundo por derecho propio, donde determinados objetos se desvelan, se traen adelante, se hacen aparecer mediante su iluminación, mientras que otros objetos se velan, quedan en el fondo o se ocultan (Insunza, 2016, p. 22).

Ese cambio conceptual se incluye en una reforma que implica "lo performativo como nueva perspectiva metodológica, lo postdramático como diagnóstico de la escena contemporánea y la idea de teatralidad como consecuencia de la expansión del campo de los estudios teatrales" (Isunza, 2016, p. 20). Un concepto central que se vislumbra con esto es la experiencia, dado que los límites entre la producción y la recepción se hacen borrosos (Insunza, 2016, p. 20).

De ese modo, "el aparecer estético, más allá del aparecer sensible (Seel), la presencia (Gumbrecht) como un asunto de potencial y marginada importancia ante la tradición del significado en las humanidades y las artes (...), abren nuevas perspectivas para entender toda experiencia del hombre con-en el mundo" (Insunza, 2016, p. 20).

Esta estética del hacer aparecer o traer al frente determinados objetos y sujetos, favoreciendo que surjan desde el fondo imágenes que quedan veladas, lo que remite a una lógica de figura-fondo. En el caso de lo postdramático, se trataría también de hacer ver eso que queda oculto en el acto de presentar, es decir, el trasfondo de la presentación, lo ominoso (Freud, 1939) y el acto mismo de la presentación, esto es, hacer ver la emoción que los actores sienten cuando interpretan una emoción. Con lo anterior, el énfasis estético queda puesto en el recorte de la realidad presentada, que se hace percibir y en las sensaciones de los propios intérpretes que hacen ver dicha realidad escenográfica, más que en tal o cual representación. 
De forma similar, en el performance art el hacer aparecer se manifiesta mediante el acontecimiento, relacionado con la ampliación de la autoría y la ampliación de los límites (González, 2016, p. 58). El acontecimiento refiere a algo que puede o no suceder, donde "el suceder estaría dado por la unión de la acción con el contexto (...) [en una práctica] que va siempre en dos sentidos a la vez" (González, 2016, p. 58): mundo interno y objetivo, memoria e imaginación, memoria colectiva e imaginario colectivo.

Deleuze (citado en González, 2016, p. 58) afirma que "solo se capta la verdad eterna del acontecimiento si el acontecimiento se inscribe también en la carne". Esto hace manifiesta la importancia de la huella. Con respecto a la ampliación de la autoría, para González (2016), es necesario hacer que todo el colectivo que experimenta un acontecimiento sea autor de su propia vivencia. Con ampliación de límites, se observan deslimitaciones espaciales, temporales y epistemológicas, ya que el acontecimiento se genera en lugares no necesariamente reservados para expresiones artísticas.

La performance puede hacer presente elementos aspectuales no restringidos al tiempo epocal, por lo que se ejerce una deslimitación con respecto a los temas disciplinares y a la representación, mediante la centración en el acto y en sus efectos performáticos de co-construcción de realidad. El performance art invita, entonces, a ampliar los límites para ser habitados por la creación (González, 2016).

Esta epistemología performática es posible gracias a una forma de conceptualizar las imágenes no como íconos, sino como medio sensitivo imperceptible que posibilita la percepción. De acuerdo con Moyano (2018, p. 71), con respecto al reflejo en el espejo, este concluye que:

"el verdadero desdoblamiento no es entre el sujeto y su reduplicación objetual en el espejo, entre el soñador y su sueño, sino entre ellos y el medio que los posibilita: las imágenes. Ellas no son lo que vemos ni lo que nos mira, sino la visibilidad en cuanto tal, el medio de la visión. Y la visibilidad, como la perceptibilidad, como la vida, es imperceptible".

De ese modo, la lógica de la figura y el fondo queda posibilitada por un entre y a través que es la sensitividad. Una forma de llamar por catacresis esta nueva concepción de las imágenes, entendida como medio sensorial imperceptible desde donde coemergen y son comprensibles sujetos, objetos e íconos, es como una estetosfera. Esto, siguiendo a Buenafuentes (2013) con respecto 
a la composición lexical, a partir de la sustitución del lexema semio del léxico compuesto "semiosfera" de Lotman (2000, 1996), por el lexema esteto, que hace referencia al léxico estética en su denotación: sensitividad o percepción sensible.

La estetosfera, como una estructura existencial ontológica desde la que se origina la estructura epistemológica sujeto-ícono-objeto de la semiosfera, permite dar cuenta de este medio envolvente de sensitividad, o en términos de Jaspers (1967), de esta imagen de mundo sensitivo-espacial, definición que claramente es anticipativa y liberadora, pues permite una mayor capacidad de acción a quienes producen y consumen imágenes, pues prácticamente todo lo sensible puede pasar a ser su objeto.

La estetosfera -siguiendo los planteamientos de Moyano (2018) con respecto a la imagen imperceptible-, se piensa como potencia, como presente, en tanto este es la negación de lo no sido, de lo ya sido y de lo aún no sido, después de lo cual queda la estetosfera como pura posibilidad o posibilidad pura de imágenes, lo que, a su vez, garantiza la sensitividad y es condición de lo que Riveros (2018, p. 21), desde Schiller, hace ver como suspensión estética.

$$
\neg \neg(\mathrm{n} \vee \tilde{n} \vee 0) \& \neg(\mathrm{p} \vee \mathrm{q} \vee r) \& \neg \neg(\mathrm{W} \vee x \vee y) \Longrightarrow(\neg \neg \& \neg \& \neg \neg)
$$

Una aplicación práctica de ir al ser de las imágenes como estetosfera, desde donde coemergen epistemológicaente sujetos y objetos mediados por imágenes mímesis, íconos, símbolos, síntesis, entre otras, la podemos ver en el pool de imágenes, de preferencia históricas que la industria de Hollywood utiliza para hacer sus estudios iniciales para la producción de películas históricas (Rich, 2019, p. 152), por ejemplo, en referencia a las obras del pintor académico francés JeanLéon Gérome, tales como "Hail, Caesar!, We Who Are About to Die Salute You (1850), The Cristian Martyrs' Last Prayer (1862-83), and Pollice Verso (1872) (...) Hollywood studios actually used copies of these paintings in their background research for productions of films set in ancient Rome" (Rich, 2019, p. 152).

Con respecto a lo dicho, se forma la siguiente heurística: desde la estetosfera se traen al frente imágenes ontológicas o comunicantes de hechos (Bleichmar \& Schwartz, 2019; Levy, 2019), que son utilizadas como unidades protocinemáticas históricas. Pero, las mismas imágenes ontológicas pueden servir para la producción de unidades protocinemáticas ficticias, si se libera el acto de traer al frente, de la lógica conceptual que es inductiva, unidireccional e histórica, propia 
del texto (Flusser, 1973), lo que remite a una contaminación de la estetosfera con la lógica epistemológica de la representación que es propia de la semiosfera.

Para lo anterior, es necesario ordenar las imágenes que se traen al frente con una actitud intuitiva (Jaspers, 1960), formando un collage o un montaje donde se proyectan relaciones no evidentes y en las cuales juega un importante papel el inconsciente de los investigadores en un automatismo propio de los surrealistas y del action painting de Pollock. Un ejemplo de ello es el Atlas Mnemosyne de Aby Warburg, historiador del arte alemán (Tartás \& Guridi, 2013).

La estetosfera como ser auténtico de las imágenes se materializa en el dispositivo conocido como "research bibles" (Rich, 2019, p. 153), donde se acumulan las imágenes en una estetosfera artefactual. Estas research bibles pueden ser consideradas como núcleos ontológicos descentralizados de las estetosfera, que, en su conjunto y articulados con otros núcleos estéticos, constituyen la "republic of images" (Rich, 2019, p. 154), de manera similar, pero también más extendida que la república de las letras iniciada por la alta cultura de los siglos XVII y XVIII.

Las imágenes traídas al frente desde estas estestosferas artefactuales, si bien buscan una preeminencia histórica, no necesariamente es así. Esto lo deja de manifiesto el Atlas Mnemosyne, pero también el mismo montaje de imágenes en el cine, que se puede dividir en dos intenciones sobre la base de la consideración de las imágenes ya no como estetosfera, sino como íconos, es decir, en su momento epistemológico, en otros términos, una vez hecho el recorte que hace emerger desde una estetosfera, ya sea natural o artefactual, determinadas imágenes.

Es a partir de este recorte en que se opta en el cine por suponer que la "imagen funciona como un doble, un espejo, un ejercicio de naturaleza objetiva que gracias a la máquina registra la realidad $u$ opta, en contraste, por ser simplemente la materialización de la subjetividad de un creador que manipula su medio conforme a sus propios fines" (Alvarado \& Escobar, 2018, p. 28).

Según Alvarado \& Escobar (2018, p. 28) esta es la tensión entre el registro o la proyección, que se manifiesta en el debate entre Rohmer y Pasolini, entre el cine prosa contra el cine poesía. Es una tensión que se condensa de forma manifiesta en la imagen síntesis, donde películas como Speed Racer (de las hermanas Wachowski) o Gravity (de Alfonso Cuarón) son ejemplos paradigmáticos. 
Alvarado \& Escobar (2018, p. 38), sobre la base de la compresión de lo real como artificio, plantean que Gravity se presenta como duplicación y esconde la técnica de producción de imágenes y Speed Racer como construcción, pues se reconoce como falsificación y muestra la técnica con la cual las imágenes se presentan ficticias. Esos filmes constituyen dos tipos de escritura de la imagen técnica del cine que se remontan a la discusión entre el cine directo de los Lumiére y el cine trucaje de Méliès (Alvarado \& Escobar, 2018, p. 38), por lo tanto, ofrecen dos tipos de pensar las imágenes que resuenan por analogías sincrónicas con la diferencia entre representación y aparición del teatro posdramático contemporáneo, donde mutatis mutandi, representación es al registro, lo que la aparición a la proyección, similitudes epitemológicas que están en relación, puesto que coemergen como una red semiosférica de núcleos conceptuales en tensión desde un mismo fondo ontológico estetosférico.

Por otro lado, entre la pintura y la poesía emerge una tensión interdisciplinar similar, que vincula estas dos expresiones artísticas, teniendo como representantes a Cézanne y Baudelaire respectivamente. Ambos, a su modo, son artistas modernos que dan una respuesta original al problema epistemológico de la objetivación de la naturaleza, la cual, al igual que en el cine y en el teatro, no se cuestiona en su ser, sino en su modo de ser y en la relación con este.

Muñoz (2016, p. 69) afirma que "Baudelaire rechaza tajantemente la naturaleza como referente del arte, mientras que Cézanne no se cansa de repetir que el pintor no puede, por ningún motivo dejar de atenderla".

En efecto, Muñoz (2016, p. 76) trae al presente la voz de Baudelaire quien sostiene que:

"no hay un mundo afuera, objetivo, estable, eterno. Solo quien cree en ese tipo de existencia puede limitarse a mostrar -0 a intentar mostrar- el mundo tal como lo ve. No se puede describir la realidad "tal cual" porque no podemos estar seguros de que tal cosa existe: la existencia de una realidad objetiva es por decirlo menos, dudosa".

Baudelaire da énfasis a dos funciones mentales fundamentales que manifiestan la temporalidad de la consciencia en tiempo pasado y en tiempo futuro: la memoria y la imaginación, respectivamente. En ellas surge lo bello (Muñoz, 2016). Incluso, la memoria permite absorber los colores, las siluetas, y es, a su vez, el filtro que permite el surgimiento del detalle significativo; lo bello no guarda relación necesaria ni con lo bueno ni con lo verdadero, incluso puede habitar el mal; la imaginación, 
entendida como potencia creadora, es la que conoce el mundo y la que hace surgir las posibilidades de futuro, por ende es la guardiana de la autonomía de lo bello (Muñoz, 2016).

Muñoz (2016) nos hace tener en mente que -para Baudelaire- no es el registro de la naturaleza lo que el artista reproduce, sino las impresiones que emergen en su mundo interno, vinculadas con la memoria, a través de equivalencias literarias y pictóricas, recompuestas por la imaginación y proyectadas en forma de belleza que dice futuro.

La imaginación del poeta remite a los polos conceptuales de la presentación del actor y de la proyección del cineasta. Estos tres polos resuenan, dando énfasis a la subjetividad del artista, plasmada en la propia actuación del actor como imagen performática, en las imágenes técnicas producidas por el cineasta o en las imágenes literarias del poeta.

Frente a esa subjetividad, el modo de la realidad natural queda puesta en duda o reconocida como artefactual, dependiendo de si emergen desde estetosferas cotidianas 0 artefactuales.

Para Cézanne, en cambio, la naturaleza debía ser observada con atención, pero no para copiarla o por pensar que esta fuera superior al arte, sino para explorar la relación entre aquella y este, para encontrar en ella un motivo para traducir las sensaciones que el motivo elicita y no para la reproducción de las apariencias dadas de antemano (Muñoz, 2016).

Hay una diferencia entre el motivo externo dado por la naturaleza y el modelo. De esa forma, el motivo es para Cézanne, "lo que el mundo sensible ofrece a la vista; el modelo en cambio son las sensaciones generadas al contacto con tal motivo, ellas son las que se traducen en pinturas" (citado en Muñoz, 2016, p. 79).

Según Muñoz (2016, p. 79), el dato sensible no es la sensación, sino que esta es "al mismo tiempo una experiencia subjetiva y una perceptual (...) una experiencia tramada con la percepción, pero que involucra también aquello que lo percibido provoca como efecto". Es decir, el objetivo del trabajo de Cézanne era la traducción eficiente de sus sensaciones al lienzo, mediante el énfasis en el color para lograr profundidad y la realización significativa, a fin de poner en el mundo algo que antes no existía y "construir la realidad" (Muñoz, 2016, p. 79). 
Entre el arte como expresión, como construcción o como mímesis, Cézanne se vierte por la construcción, al poner en el mundo algo que con anterioridad no estaba. Si bien compartía con Baudelaire la idea de no realizar una mímesis del modelo, deja un espacio para la participación de este en la forma de motivo.

La imaginación desde la poesía en Baudelaire y la construcción desde la pintura en Cézanne son dos salidas a la mímesis realista naturalista del modelo. Son discusiones que constituyen el tiempo epocal de la modernidad y que se proyectan hacia la posmodernidad, junto con las discusiones entre aparecer y representar del teatro y la proyección y registro del cine. Todas son formas epistemológicas de pensar la relación entre el sujeto, el objeto y las imágenes.

Por otro lado, con respecto a la música, es posible observar una nueva tensión, entre la experiencia de la obra de arte particular y lo que, de acuerdo a De la Grange (citado en Salaberry 2017), es la obra de arte total, donde toma protagonismo la puesta en escena más allá de lo musical. Tristán e Isolda de Wagner, obra que fue producida por Mahler y presentada en 1903 en Viena, la cual es considerada el primer espectáculo lírico moderno con los parámetros de la obra de arte total (De La Grange citado en Salaberry, 2017). En ella, Salaberry (2017, p. 35) asevera que "todos y cada uno de los elementos debían dirigirse hacia un mismo objetivo, esto es, conformar una expresión global que tuvo como meta llegar a la esencia de la obra".

En elámbito de la composición musical, Mahler cambió el sistema composicional tradicional. La organización tonal se configuró como "un sistema de composición jerárquico, direcciones y resolutivo: notas de mayor importancia que realizan una dinámica de tensión y reposo, donde la secuencia de notas debe dirigirse hacia una resolución, que es la nota de reposo" (Salaberry, 2017, p. 37). Incluso, Malher, con la persistencia de la resolución y la direccionalidad, crea con la "estrategia de la politonía (...) la posibilidad de una resolución múltiple de la pieza musical, es decir, una secuencia de notas posibles de ser dirigidas hacia distintos centros tonales o notas de reposo; esto se traduce en lo que aquí denominamos una direccionalidad fragmentada, que fractura la unidad resolutiva de la composición" (Salaberry, 2017, p. 37).

Asimismo, Mahler, junto con las actualizaciones de lirismo sinfónico al introducir canciones y poemas contemporáneos en obras sinfónicas clásicas, cambió la lógica de la tensión polar entre el modo mayor y menor, relacionados 
con la alegría y con el sufrimiento respectivamente, los cuales tradicionalmente se utilizaban en una tensión donde el modo menor se empleaba en función del modo mayor. Mahler volvió esa relación ambivalente y simultánea, logrando expresar algo nuevo, una emoción original, que no se reduce a la tonalidad emotiva clásica que oscila entre alegría y sufrimiento-melancolía (Salaberry, 2017).

Salaberry (2017) argumenta que con los cambios descritos, Mahler hacía revivir cada obra del pasado desde su propia perspectiva, no imitándola, sino recreándola al modo de la modernidad. La obra no es repetida irreflexivamente, por el contrario, es convertida en objeto de pensamiento, criticando con esto no la obra en sí, sino la producción repetitiva de la misma en el presente o el tradicionalismo, pero desde la tradición.

La obra musical no necesita un referente al que imitar. Es una analogía del mundo externo, pero también del mundo interno -tal como en la pintura abstracta y conceptual-, las tensiones conceptuales observadas no son asimilables a las de las otras expresiones artísticas, sino inmanentes a su propia estructura. Se evidencian tres tensiones que caracterizaron la actualización de la tradición en la música clásica, mediante una objetivación de la misma desde el presente, lo que significó un salto a la modernidad de la mano de Mahler.

Lo anterior implicó el paso desde la obra de arte particular hacia la obra de arte total, así como el cambio de un sistema composicional jerárquico, unidireccional y resolutivo a una resolución múltiple y una direccionalidad fragmentada. Asimismo, se produjeron actualizaciones en el lirismo sinfónico, mediante la introducción de poesía y canto popular moderno. Pero, el cambio, quizás, más importante es el de la subjetividad que se construye (Janeiro, 2018), con las emociones que encarna, expresa, comunica y suscita (Sixto, 2017). La variación de la tensión polar entre los modos mayor y menor (desde un modo menor en función del modo mayor), hacia una relación modal ambivalente y simultánea que encarna, expresa, comunica y suscita una emoción original, participa en la construcción de una subjetividad moderna, siendo también posible que -con el cambio composicional nombradose haya iniciado el avance a la subjetividad posmoderna, del mismo modo en que cada movimiento tiene en su seno la semilla de su superación.

Así, a partir del análisis de textos se han sacado a la luz y analizado algunos de los conceptos que componen uno de los paisajes estéticos y artísticos contemporáneos, el cual se conforma de relieves conceptuales que coemergen 
ontológicamente desde la estetosfera y epistemológicamente desde las superficies disciplinares más amplias, conformando sincrónicamente una red semiosférica descentrada de núcleos conceptuales en tensión.

\section{Ser sí-mismo en su fe-proyección}

Con los Lumiére, los Méliès, Cezanne, Baudelaire y con Mahler, se han dejado en evidencia algunas de las tensiones conceptuales que constituyeron la modernidad. También, con la tensión conceptual observada en el teatro posdramático y con la lógica del acontecimiento del performance art se han delineado algunos elementos conceptuales que participan del juego eidético posmoderno. ¿Pero cuáles son las reglas de dicho juego en relación a la modernidad y en particular a las vanguardias de la modernidad tardía?

Con respecto a la interrogante anterior, una respuesta clarificadora del deplazamiento es enarbolada en 1987 por el periódico del Museo Nacional de Arte Moderno de París (Les Cahiers du Musée National d'Art Moderne, director: Yves Muchaud):

"Los síntomas de un período posmoderno no son difíciles de distinguir. Los cubos amenazantes de los modernos bloques de apartamentos suburbiales se han transformado en construcciones que quizá sigan siendo cubos, pero han sido cubiertos con ornamentos estilizados. El ascetismo puritano, o simplemente aburrido, de las diversas formas de pintura abstracta (hard-edged o colour field, o postpainterly) ha sido reemplazado por pinturas alegóricas o manieristas, frecuentemente figurativas... llenas de alusiones a la tradición y la mitología. En escultura, los objetos compuestos, de "alta tecnología" o burlones, han sustituido a las obras que se cuestionaban la autenticidad del material o la tridimensionalidad. Los artistas ya no se abstienen de narrar, discursear o moralizar... Al mismo tiempo, los administradores y burócratas del arte, la gente de los museos, los historiadores de arte y los críticos han perdido o abandonado su firme creencia en la historia de las formas que hasta hace muy poco se identificaban con la pintura abstracta estadounidense. Se han abierto, para bien o para mal, a una diversidad a la que ya no le preocupan las vanguardias" (citado en Gombrich, 1999, p. 619).

Por otro lado, en 1988, John Russell Taylor escribió en The Times, con respecto a la hipótesis de este trabajo: 
"Quince o veinte años atrás sabíamos con bastante claridad lo que queríamos decir con moderno y qué tipo de cosa, aunque fuera aproximadamente, podíamos esperar ver si acudíamos a una exposición que hacía publicidad de su adscripción a la vanguardia. Pero ahora, claro está, vivimos en un mundo pluralista en el que con frecuencia lo más avanzado, probablemente posmoderno, puede parecer lo más tradicional y retrógrado" (citado en Gombrich, 1999, p. 619).

Entendiendo lo posmoderno como tiempo epocal, a través y más allá del arte posmoderno, el ánimo de los tiempos es que "se tiene por posmoderna la incredulidad con respecto a los metarrelatos. Esta es, sin duda, un efecto del progreso de las ciencias; pero ese progreso, a su vez, la presupone" (Lyotard, 1987, p. 4). En efecto, "el legitimar el saber por medio de un metadiscurso va a caracterizar a la cultura moderna. En contraposición, el paradigma posmoderno se va a caracterizar por ser escéptico respecto a esta clase de grandes relatos" (Steinlen, 2016, p. 13).

De ese modo, las vanguardias tales como: fauvismo, expresionismo alemán, expresionismo de la escuela de París, cubismo, futurismo italiano, abstracción, dadaísmo, surrealismo, constructivismo ruso, la escuela de la Bauhaus y el funcionalismo en arquitectura (Cirlot, 1988), el opt art y el pop art (y su énfasis elitista, rupturista, su rechazo al modelo natural y la tradición de lo nuevo por sobre el pasado) se saturan y se vuelven contrarios, haciendo que lo nuevo y la ruptura dejen de sorprender o dejen de asimilarse a la originalidad, y se conviertan en una regla, en la que ya no es posible diferenciar una obra de arte de un objeto común, dando paso al cambio de marea posmodernista, un término que fue "introducido en la discusión en 1.975 por Charles Jencks, un joven arquitecto cansado de la doctrina del funcionalismo" (Gombrich, 1999, p. 620).

En el posmodernismo prima más que un cambio de técnicas, un cambio de humor y la múltiplicación de relatos legitimadores alternativos, por ejemplo: con la introducción de lo lúdico en las formas arquitectónicas más bien serias de la Bauhaus, saliendo a la luz la escuela Memphis y el color, siguiendo nuevamente a la forma cuando esta se libera de la función y entra en el juego conceptual lúdico e irreverente para dar forma a una composición original, a pesar de la función. Con la salvedad de que el juego artístico "es el afán estético disruptivo del arte, lo más serio de la existencia" (Ríos-Espinosa, 2019, p. 212), sin tomarse uno mismo en serio. 
Al respecto, "la mayoría de críticos estaban convencidos de que solamente las desviaciones más radicales respecto a la tradición conducirían al progreso" (Gombrich 1999, p. 402). Hoy, en cambio, la pluralidad, el diálogo, lo lúdico y la tolerancia, por ejemplo, al retorno del modelo natural, es horizonte de sentido. Esto se puede observar en las obras de Lucian Freud o en la valoración de la fotografía (Gombrich, 1999).

Esas características se pueden apreciar también en la exposición de WarholBasquiat Painting's de 1985. "En estas obras se misturaban los relatos del pop art con el neoexpresionismo de Basquiat, sin la necesidad de imponer uno sobre el otro" (Steinlen, 2016, p. 13). Según Steinlen (2016, p. 16) con esas obras no solo se rompe con "el arte moderno de los manifiestos, donde un estilo tenía que quebrar con el anterior, sino que establecen que si bien los diferentes estilos artísticos deben convivir sin pasar unos sobre otro, también se pueden mezclar y crear una especie de collage".

\section{Conclusión}

Volviendo al principio, al performance arty al teatro posdramático, al acontecimiento. Esto es lo más avanzado y, a la vez, lo más tradicional. La presencia en relación a la representación en el teatro, en palabras de Gumbrecht (citado en Inzunza, 2018, p. 22), se inscriben oscilatoriamente en "una "cultura de presencia" y "cultura de significado", relacionando la primera con una cultura medieval y la segunda con una cultura moderna". La primera es como un candelabro que ilumina las sombras y hace presente los objetos y los sujetos inmediatos, por lo que la sensibilidad y el tacto es esencial; mientras que, la segunda es un espejo que refleja o representa los sujetos y objetos de otros contextos.

Por su parte, y con el mismo horizonte de sentido, el método humanístico de Ciocchini descrito anteriormente, implica ontoespistemológicamente:

" 'desprenderse de Francia', de París y la tradición iluminista [lo que implica el] redescubrimiento de Roma, de la Roma aeterna, de la Ciudad Santa, no sólo en cada una de sus capas históricas, sino en su esencia psíquica, o sea en un sentido supra-histórico', (...) 'la idea imperial de Roma como patrón eternamente válido de la humanidad', sobre la base de 'un nuevo Humanismo' que 'no debe enlazar ni con la Antigüedad ni con el Renacimiento sino con la Edad Media' y que, por consiguiente, 'no debe ser un clasicismo, sino un medievalismo y una actitud de restauración"' (Curtius citado en Crespi, 2018, p. 53-54). 
Lo anterior es interpretado como indicios culturales microhistóricos (Ginzburg, 2004) que confirman la hipótesis de que lo más avanzado coincide con lo más tradicional en el tiempo epocal posmoderno, por el contrario, no se encontraron indicios que refutaran dicha hipótesis.

El hacer aparecer ontoespistemológico como mínimo común conceptual de las expresiones artísticas estudiadas coincide en parte con elementos culturales del medioevo. Por tanto, la suposición es que se trae nuevamente a la luz dicho mundo, pero actualizándolo como lo hizo Mahler con la obra de arte total y los cambios composicionales, modales y líricos. De esto es indicio, el que la obra de arte más costosa subastada hasta el momento corresponda al cuadro Salvator Mundi (de la autoría de Leonardo Da Vinci y vendida en 2017).

Además, el hecho de que las nuevas tendencias traigan del pasado elementos de la edad media o del renacimiento, coincide con una vuelta al modelo, a las formas y claramente un retorno al humanismo, que ha estado mucho tiempo en crisis, arrinconado por el progreso indiscriminado de la técnica y del saber racional (Gandolfo, 2018).

Sin embargo, que estas proyecciones se hagan efectivas, depende de la maduración del polysensum plurium sensuum en la temporeidad epocal.

\section{REFERENCIAS BIBLIOGRÁFICAS}

ALVARADO, C. \& ESCOBAR, J. (2018). "Imágenes realistas contra imágenes plásticas. Variaciones de la imagen cinematográfica en Gravity de Alfonso Cuarón y en Speed Racer de Lily y Lana Wachowski". Arte, Individuo y Sociedad, 31(1), pp. 27-40.

BAJTIN, M. (2011). Estética de la creación verbal. Madrid: Siglo XXI.

BAJTIN, M. (1988). Problemas de la poética de Dostoievski. México: FCE.

BLEICHMAR, D. \& SCHWARTZ, V. (2019). "Visual History: The Past in Pictures". Representations, Vol. 145, № 1, pp. 1-31.

BUENAFUENTES, C. (2013). "Tratamiento lexicográfico de los compuestos léxicos y cultos en los diccionarios del español". Revista de Filología Española. XCIII, $2^{\circ}$, pp. 241-271. 
CASTORIADIS, C. (2007). La institución imaginaria de la sociedad. Buenos Aires: Tusquets.

CIRLOT, L. (1988). Las claves de las vanguardias artísticas en el siglo XX. Cómo identificarlas. Barcelona: Editorial Ariel.

CRESPI, M. (2018). "Filología y estilística como modelos de la investigación humanística en Héctor Chocchini”. Boletín de Estética, año XIV, № 44, pp. 33-63.

FLUSSER, V. (1973). Línea y Superficie (A. Soto Trad.). Valparaíso.

FREUD, S. (1919). "Lo ominoso". En De la historia de una neurosis infantil y otras obras [1917-19], (ed. Janmes Strachey, Trad. José Etcheverry). Buenos AiresMadrid: Amorrortu Editores.

GANDOLFO, P. (2018). "El lugar de las humanidades en la formación". UC Maule Revista Académica, № 55, pp. 33-34.

GINZBURG, C. (2004). Tentativas. Buenos Aires: Ediciones Protohistoria.

GOMBRICH, E. H. (1999). La historia del arte. México D.F: Editorial Diana.

GONZÁLEZ, F. (2016). "Ideas de una investigación en curso. Sobre la posibilidad de efectos político-artísticos a partir de la práctica del performance art". Revista de Teoría del Arte. № 29, pp. 51-66.

GRONDIN, J. (1999). Introducción a la hermenéutica filosófica. Barcelona: Herder.

HALBWACHS, M. (2004). La memoria colectiva (trad. de Inés Sancho-Arroyo). Zaragoza: Prensas Universitarias de Zaragoza.

HEIDEGGER, M. (2015). Ser y Tiempo (Trad. J. E. Rivera). Santiago: Editorial Universitaria.

HEIDEGGER, M. (1994). "La pregunta por la técnica". En Heidegger, M. Conferencias y artículos. Barcelona: Ediciones del Serbal.

HERACLITO. (2009). "Fragmentos filosóficos de Heráclito en García". En Los presocráticos (Comp. Juan David). México D.F: Fondo de Cultura Económica. 
INSUNZA, I. (2016). "Gumbrecht, Seel y Rancière: Perspectivas estéticas para pensar el teatro contemporáneo". Revista de Teoría del Arte, № 29, pp. 19-27.

JANEIRO, J. (2018). "Collage de identidades - Un simulacro del yo en el arte contemporáneo". Anales de Historia del Arte, 28, pp. 177-199.

JASPERS, K. (1960). Psicología de las concepciones de mundo. Madrid: Editorial Gredos.

JASPERS, K. (1933). Ambiente espiritual de nuestro tiempo. Barcelona-Buenos Aires: Editorial Labor.

LEVY, E. (2019). "Eyewitnessed Historia and The Renaissance Media Revolution: Visual Histories of the Council of Trent". Representations, Vol. 145, № 1, pp. 5579.

LIZCANO, E. (2006). Las metáforas que nos piensan. Sobre ciencia, democracia y otras poderosas ficciones. Madrid: Editorial Traficante de Sueños / Ediciones Bajo Cero.

LOTMAN, Y. (2000). La Semiosfera III. Semiótica de las artes y de la cultura. Madrid: Ediciones Cátedra.

LOTMAN, Y. (1996). La Semiosfera I. Semiótica de la cultura y del texto. Madrid: Ediciones Cátedra.

LYOTARD, J.-F. (1987). La condición postmoderna. Informe sobre el saber (Trad. Mariano Antolín). Buenos Aires: Ediciones Cátedra.

MIRANDOLA, P. (1984). La dignidad del Hombre, (ed. Luis Martínez). Madrid: Editorial Nacional.

MOYANO, M. (2018). "Beckett. Una imagen imperceptible". AISTHESIS № 64, pp. 53-72.

MUÑOZ, M. (2016). "Cézanne y Baudelaire: modelos de modernidad". Revista Teoría del Arte, № 29, pp. 67-82. 
PANOFSKY, E. (1955). Meaning in the visual Arts. Garden City, N. Y.: Doubleday Anchor Books.

PONCAIRE, H. (1914). Ciencia y método (trad. Emilio Méndez). Biblioteca Digital del ILCE.

RICH, A. (2019). "The Accent of Truth: The Hollywood Research Bible and the Republic of Images". Representations, Vol. 145, № 1, pp. 152-173.

RÍOS-ESPINOSA, C. (2019). "Arte y estética de la disrupción". Arte, Individuo y Sociedad, 31 (1), pp. 199-213.

RITZER, G. (2012). Teoría sociológica clásica. México: McGraw-Hill.

RIVEROS, J. (2017). "Schiller y la política singular del estado estético". Revista de Teoría del Arte, № 31/32, pp. 2-27.

SALABERRY, J. (2017). "La pintura de Cézanne y la música de Mahler: experiencia, singularidad, actualización. Revista de Teoría del Arte, № 31/32, pp. 28-41.

STEINLEN, C. (2016). "Arthur C. Danto y El Fin de los metarrelatos: El caso de la exposición 'Warhol-Basquiat Paintings de 1985"'. Revista de Teoría del Arte, № 29, pp. 9-27.

SIXTO, C. (2017). "Una aproximación al complejo emotivo del arte". AISTHESIS № 62, pp. 67-83.

TARTAS, C. \& GURIDI, R. (2013). "Cartografías de la memoria. Aby Warburg y el Atlas Mnemosyne”. EGA Expresión Gráfica Arquitectónica, № 21, pp. 226-235.

VALERY, P. (2018). La invención estética y otros escritos sobre arte. Madrid: Casimiro.

ZWEIG, S. (2019). El misterio de la creación artística. Madrid: Ediciones Sequitur. 